\title{
The development of tolerance to morphine under discrete-trial fixed-ratio, automaintenance, and negative automaintenance procedures
}

\author{
MITCHELL PICKER, DEBORAH GROSSETT, ROBERT SEWELL, \\ BRIAN ZIMMERMANN, and ALAN POLING \\ Western Michigan University, Kalamazoo, Michigan 49008
}

\begin{abstract}
The development of tolerance to morphine was examined under discrete-trial procedures in which (1) keypecks produced food delivery (fixed ratio 1), (2) keypecks had no effect on food delivery (automaintenance), and (3) keypecks prevented food delivery (negative automaintenance). Morphine at doses of 8 and $16 \mathrm{mg} / \mathrm{kg}$ initially decreased pecking under each procedure. Tolerance to morphine rapidly developed in all birds under the fixed-ratio procedure and in three of four birds under the automaintenance procedure. However, under the negative automaintenance procedure, tolerance failed to develop in all birds. These findings generally are in keeping with an analysis of tolerance that emphasizes drug-induced reinforcement loss and gain as determinants of tolerance development.
\end{abstract}

Tolerance refers to a diminished drug effect with repeated exposure and can be demonstrated by showing that dose-response curves shift to the right with repeated exposure or, alternately, by showing that chronic exposure to a given dose produces a progressively smaller effect. One factor that has been posited to influence the development of tolerance to the behavioral effects of various compounds is the consequences of drug-induced changes in behavior. The "reinforcement-loss hypothesis," advanced several years ago by Schuster, Dockens, and Woods (1966), emphasizes the potential importance of this variable: "Behavioral tolerance will develop in those aspects of the organism's behavioral repertoire where the action of the drug is such that it disrupts the organism's behavior in meeting the environmental requirements for reinforcement. Conversely, where the actions of the drug enhance, or do not affect, the organism's behavior in meeting reinforcement requirements, we do not expect the development of behavioral tolerance" (Schuster et al., p. 181).

Several studies have compared chronic drug effects under alternating conditions in which drug-induced changes in responding do and do not decrease reinforcement rate. The usual paradigm involves the use of twocomponent multiple schedules, with the components arranged so that drug-induced changes in response rate necessarily decrease reinforcement frequency in one component, but not the other. Under these conditions, reinforcement loss apparently plays a role in the develop-

We thank the members of the Behavioral Pharmacology Laboratory for their comments on an earlier version and Jeff Gallus of Science Graphics for figure preparation. Manuscript preparation was supported by a faculty research fellowship awarded to Alan Poling by Western Michigan University. ment of tolerance to cocaine (Woolverton, Kandel, \& Schuster, 1978), amphetamine (Schuster et al., 1966), and te trahydrocannabinol (Ferraro, 1978).

Chronic effects of the narcotic analgesics also have been examined under multiple schedules in which druginduced changes (decreases) in response rate reduce reinforcement under one component (e.g., a fixed ratio, or FR), but not the other (e.g., a fixed interval, or FI). Data from such studies do not unequivocally support the reinforcement-loss hypothesis, for a number of investigations have found that tolerance did not develop as readily under an FR component, in which the drug initially decreased reinforcement rate, as under an FI component, in which reinforcement loss was small or nonexistent. Other studies, however, do provide support for the reinforcement-loss hypothesis (see Krasnegor, 1978).

The purpose of the present study was to investigate the development of tolerance to morphine under discre tetrial procedures in which responses (1) are required for the delivery of food (FR 1), (2) have no effect on the delivery of food (automain tenance), and (3) prevent the delivery of food (negative automaintenance). Poling and Appel $(1978,1979)$ have examined the acute effects of several drugs, including morphine, under automaintenance and negative automaintenance procedures, but chronic drug effects have not been examined under such procedures, nor under discrete-trial FR schedules. However, each of these procedures engenders persistent keypecking by food-deprived pigeons and, therefore, should be a suitable assay of chronic drug effects.

\section{METHOD}

Subjects and Apparatus

Twelve experimentally naive White Carneaux pigeons, main- 
tained at $80 \%$ of free-feeding weights, served as subjects. They were tested in three identical operant conditioning chambers, each $38 \mathrm{~cm}$ high, $30 \mathrm{~cm}$ wide, and $40 \mathrm{~cm}$ long. The work panel of each chamber was equipped with a $2.5-\mathrm{cm}$-diam response key located $24 \mathrm{~cm}$ above the floor and $12 \mathrm{~cm}$ from the left side wall. Key illumination was supplied by a $7-W$ green bulb located behind the key. Key operation required a force of approximately $.07 \mathrm{~N}$. A grain magazine, filled with mixed grain, was horizon tally centered in the work panel $8 \mathrm{~cm}$ from the floor. A 7-W white bulb illuminated the magazine opening when the magazine was raised, and a 7-W white bulb located in the chamber's ceiling provided constant ambient illumination. Electromechanical equipment located in a room adjacent to the chambers controlled experimental events and recorded data.

\section{Procedure}

Each bird was initially trained to consistently approach and eat from the raised grain magazine. Following magazine training, the subjects were divided into three groups of four, each exposed to one of three discrete-trial procedures: FR 1, automaintenance, or negative automaintenance. Under each procedure, the key was illuminated in green once each minute, on the average, without regard to the subject's behavior. For the birds in the automaintenance group, the key was illuminated for an $8 \mathrm{sec}$ trial followed by 4 -sec access to food, irrespective of the bird's actions. Conditions were identical under the negative automaintenance procedure if the bird failed to peck the lighted key. However, the first keypeck during a trial extinguished the key light; food was not presented following such trials. Birds in the FR 1 group were exposed to the automaintenance procedure described above until the lighted key consistently evoked pecking (five sessions). At that time, a positive response-food dependency was introduced such that the first peck during a trial terminated key illumination and produced 4-sec access to food; trials in which a peck did not occur ended without food delivery following $8 \mathrm{sec}$ of key illumination. For all subjects, daily sessions terminated after 40 trials and keypecks in the absence of green key illumination had no programmed effects.

Morphine was chronically administered to each bird when the percentage of key illuminations (trials) with at least one response was stable (i.e., showed no visually obvious upward or downward trend) across five consecutive control sessions. Isotonic saline solution $(1 \mathrm{ml} / \mathrm{kg})$ was injected intramuscularly $15 \mathrm{~min}$ prior to these and all other control sessions. During drug sessions, a commercially prepared solution of morphine sulfate (Lilly, Indianapolis) diluted with isotonic saline to a $1.0 \mathrm{-ml} / \mathrm{kg}$ injection volume was injected intramuscularly $15 \mathrm{~min}$ prior to the experimental session. Within each group, two birds received $8 \mathrm{mg} / \mathrm{kg}$ of morphine (total salt), and two birds received $16 \mathrm{mg} / \mathrm{kg}$. Each bird received morphine during an initial determination and a replication. During each regimen, the drug was given chronically until the percentage of trials with at least one response during three consecutive sessions was within $\pm 10 \%$ of the mean level obtained in the five control sessions preceding drug administration or until drug was given prior to nine consecutive sessions, whichever came first. Following conclusion of the first drug regimen, subjects received saline injections until responding again stabilized (above), at which time a second drug regimen identical to that described above was initiated. A minimum of 10 control sessions separated the two drug regimens.

\section{RESULTS}

Figure 1 shows the percentage of trials with a response for each bird during control (predrug) and drug sessions. The discrete-trial FR 1 and automaintenance procedures engendered pecking during nearly all trials in control sessions. Under the negative automaintenance procedure, two birds responded during approximately $70 \%$ of the trials during baseline sessions and two birds responded less often. During both regimens, the initial administration of morphine decreased the percentage of trials with a response for all subjects, although the magnitude of this effect varied greatly across subjects, and total cessation of responding was more commonly observed under the negative automaintenance procedure than under the other procedures. Tolerance developed rapidly in all birds exposed to the discrete-trial FR 1 procedure and in three of the four birds exposed to the automaintenance procedure. According to the criteria used in this study, tolerance was never evident under the negative automaintenance procedure.

\section{DISCUSSION}

The finding that pecking was consistently engendered by the discrete-trial FR 1, automaintenance, and negative automaintenance procedures in the present study is consistent with earlier reports (e.g., Poling \& Appel, 1978, 1979), as is the finding that morphine initially decreased responding under these procedures. Both the automaintenance and negative automaintenance procedures paradigmatically involve respondent conditioning, in that a conditional stimulus, key illumination, reliably precedes the unconditional stimulus of food delivery. Through this pairing, the conditional stimulus comes to evoke a directed conditional response, keypecking, that is topographically similar to the unconditional response elicited by food. In negative automaintenance, keypecking may be weakened by an operant dependency (i.e., the response prevents food delivery), whereas automaintained keypecking may be operantly strengthened by the close, although not required, temporal proximity of pecking and food delivery. This difference in operant contingencies usually results in less frequent pecking under the negative au tomaintenance procedure, an effect evident in the present study and in earlier investigations (e.g., Poling \& Appel, 1978, 1979).

Comparison of chronic morphine effects under the three procedures is of some interest, since the drug initially affected the frequency of food delivery under each differently. The reinforcement-loss hypothesis predicts that tolerance should develop most rapidly under the FR 1 schedule, in which the initial effect of morphine was a reduction in the number of food deliveries, and less readily if at all under the negative automaintenance procedure, in which drug-induced decreases in pecking increased the frequency of food delivery. The present data are consistent with this hypothesis, since tolerance always developed under the FR 1 but was never evident under the negative automaintenance procedure. Tolerance also developed in three of four birds under the automaintenance procedure, in which druginduced decreases in keypecking failed to affect food delivery.

However, caution is required in interpreting the present data, for baseline levels of responding were lower under the negative automaintenance procedure than under the FR 1 and automaintenance procedures. In addition, morphine nearly completely suppressed responding under the former procedure, but not under the latter two. Either of these factors, as well as relative reinforcement loss or gain, could have affected the development of tolerance. A truly adequate test of the reinforcement-loss hypothesis seemingly would require comparable baseline levels of responding and initial drug effects under all conditions, but it is not easy to see how this could be arranged with the procedures employed in the present study, nor those used in earlier investigations. Given this, the reinforcement-loss hypothesis may long remain unproved, if provocative. 


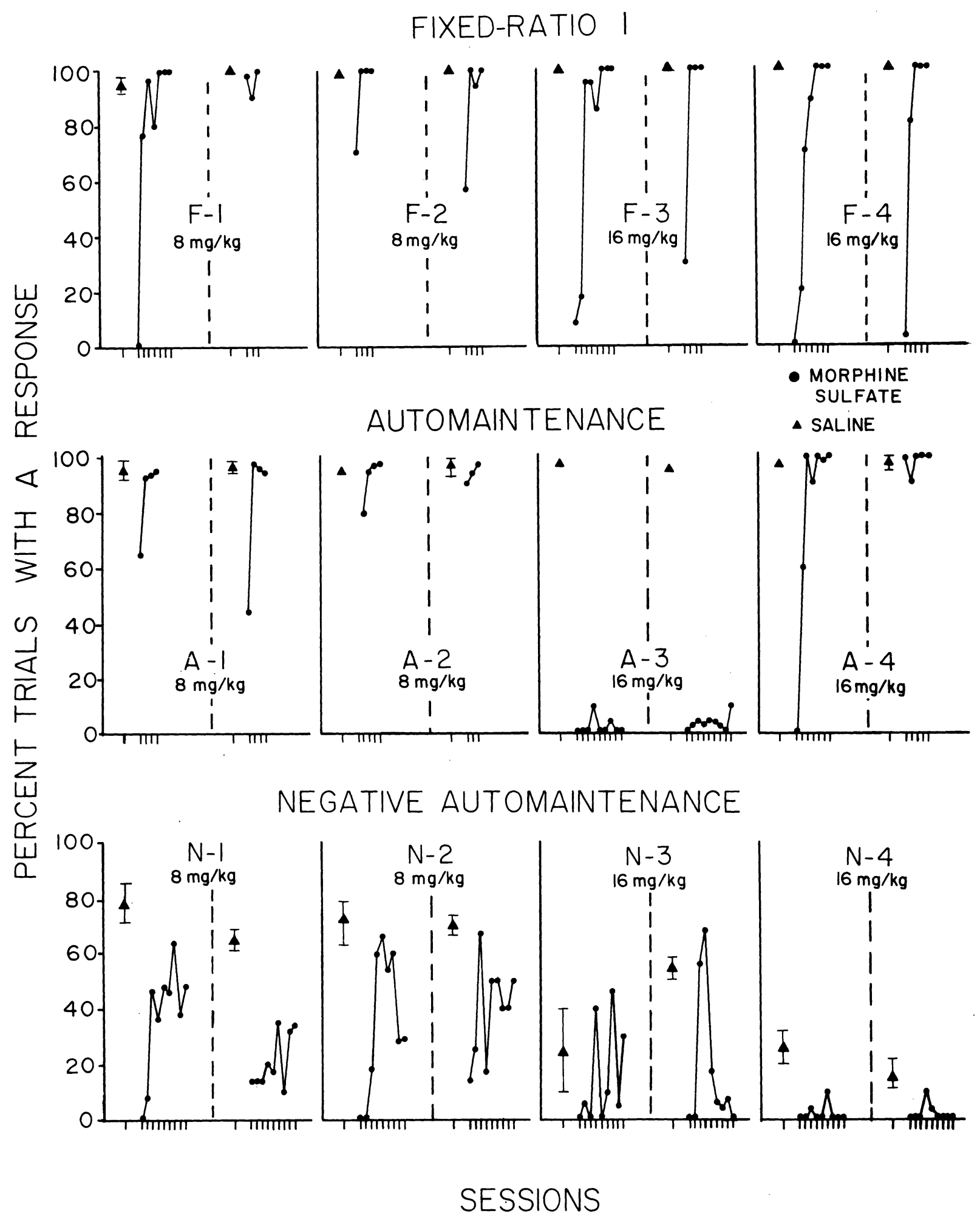

Figure 1. Percentage of trials with a response by each pigeon during all experimental conditions. Triangles represent mean performance across five control (saline) sessions prior to drug administration; vertical lines represent \pm 1 standard deviation. Circles represent performance during individual sessions preceded by morphine administration. In each of the two drug regimens, morphine was given prior to nine consecutive sessions or until the percentage of trials with at least one response during three consecutive drug sessions was within $\pm 10 \%$ of the mean level obtained in the five control sessions preceding drug administration, whichever came first. The three procedures are explained in the text. 


\section{REFERENCES}

Ferraro, D. P. Behavioral tolerance to marihuana. In N. A. Krasnegor (Ed.), Behavioral tolerance: Research and treatment implications. Rockville, Md: Department of Health, Education, and Welfare, 1978.

Krasnegor, N. A. (Ed.). Behavioral tolerance: Research and treatment implications. Rockville, Md: Department of Health, Education, and Welfare, 1978.

Poling, A., \& Appel, J. B. Drug effects under automaintenance and negative automaintenance procedures. Pharmacology, Biochemistry and Behavior, 1978, 9, 315-318.
Poling, A., \& Appel, J. B. Drug effects on the performance of pigeons under a negative automaintenance schedule. Psychopharmacology, 1979, 60, 207-210.

Schuster, C. R., Dockens, W. S., \& Woods, J. H. Behavioral variables affecting the development of amphetamine tolerance. Psychopharmacologia, 1966, 9, 170-182.

Woolverton, W. L., Kandel, D., \& Schuster, C. R. Effects of repeated administration of cocaine on schedule-controlled behavior of rats. Pharmacology, Biochemistry and Behavior, 1978, 9, 327-337.

(Received for publication January 18, 1982.) 